\title{
On the Diversification of Innovation and Entrepreneurship Curriculum Objectives
}

\author{
Delin Sun ${ }^{1}, \mathrm{Yu} \mathrm{Li}^{1}$, Guanghua $\mathrm{Li}^{2}$, Ying $\mathrm{Yu}^{1}$, Jiaxin Luo ${ }^{1}$ \\ ${ }^{1}$ Jiangxi Normal University, Nanchang, Jiangxi,China \\ ${ }^{2}$ Nanchang Institute of Science \& Technology, Nanchang, Jiangxi,China \\ 1835009122@qq.com
}

\begin{abstract}
Keywords: Innovation and entrepreneurship; Curriculum objectives; Diversification; Informatization education

Abstract. Under the background of innovation and entrepreneurship education comprehensive reform, this paper explores on the characteristics, functions and focus of innovation and entrepreneurship curriculum objectives, which has a significant meaning.
\end{abstract}

\author{
创新创业课程目标多样化探讨

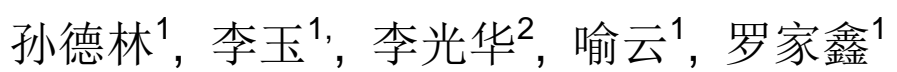 \\ 1江西师范大学, 南昌, 江西, 中国 \\ 2南昌工学院, 南昌, 江西, 中国 \\ 1835009122@qq.com
}

关键词：创新创业；课程目标；多样化；信息化创新创业教育

摘要. 在创新创业教育综合改革背景下, 本文对创新创业课程目标多样化特征、功能、关注 点等相关问题进行了研究, 其研究意义深远。

\section{1. 引言}

在二十世纪七十年代, 西方发达国家为加强以高校为基础的创新创业教育, 推动课程多 样化的发展。创新创业课程多样化正成为一种创新创业课程政策, 而创新创业课程多样化政 策通常旨在把现有的普通高等学校的创新创业课程实现多样化, 这已成为全球高等创新创业 教育研究的热点问题。比如美国, 其创新创业教育已系统地进入学科领域, 拥有100多个创新 创业研究中心、多种学术期刊, 其中具有 5 种公认的权威期刊。而我国创新创业教育领域还处 于初期发展阶段。由于传统思想的 “学而优则仕” 的思维定势, 大多数人上大学的目的普遍 是为了获得文凭、找个安稳的好工作，而不愿意冒险创新创业。而且，现实社会也的确是走 仕途的人更安稳、更有成就感, 只要不犯大的错误, 都会有个好结果, 当前持续升温的公务 员考试热, 上千人竞争一个公务员岗位的局面也正说明了这一点。创新创业教育缺失, 造成 学生创新创业能力欠缺。

近十年来，我国创新创业教育研究逐渐发展并受到广泛的重视，尽管我国各类院校陆续 开设了创新创业相关课程, 但由于起步较晚, 我国高校对创新创业教学的导向、师资构建、 教学平台等方面仍处在探索阶段。显然要想全面推动创新创业教育, 必须在人才培养目标中 将培养创新创业人才纳入其中, 纳入课程目标中, 只有这样, 课程体系才能在人才培养的目 标和课程目标指引下, 进行课程结构与课程内容的优化, 使创新创业理论和实践课程在整个 
课程体系中与其它课程有机融合并占有一定的结构比例, 摆脱创新创业教育脱离主流专业教 育的状况。我国的创新创业计划大赛得到了越来越广泛的关注和认识。创新创业教育可通过 课堂或创新创业大赛实现创新创业教学。创新创业课程是理论与实践结合紧密的课程, 该课 程涉及创业机会、创新创业团队、创业融资、创新创业基本步骤以及对初创企业各方面管理 等多方面内容。课程多样化最早是出现于二十世纪二三十年代, 代表人物有: 托斯顿胡森

(Torsten Husen) 和纳维尔波斯特尔斯威特（T Neville Postlethwaite）。为了让学生全面客观 准确地掌握创新创业课程的知识, 有必要探索课程目标的多样化。在创新创业教育综合改革 背景下, 本文在本团队多个研究课题的基础上, 对创新创业课程目标多样化的特征、功能、 关注点等相关问题进行了探讨，其研究意义深远。

\section{2. 创新创业课程目标多样化特征}

课程目标会影响着教学活动的开展, 创新创业课程目标既要考虑社会对创新创业人才的 要求, 又要考虑学生个性的发展, 这就要求创新创业课程要有比较系统的、符合经济社会发 展的基本要求, 使全体大学生学习创新创业课程后能够达到创新创业的基本要求, 同时又能 满足学生多样化的个性需求以及社会所需的创新创业人才的要求, 并且根据学生个性需求的 不同制定出创新创业课程多样化的课程目标 ${ }^{[1]}$ 。创新创业课程目标多样化特征主要表现为: 导向性。“导向性” 是指创新创业课程目标在一定程度上确定着创新创业课程开发与教学设 计的方向, 它使师生在整个教学活动中有明确的指向。使他们了解创新驱动国家战略要求以 及目前我国大学生严峻的就业形势、社会对人才需求的多样化和巨大的社会就业压力, 认识 到创新创业课程目标多样化的重要意义。激励性。目标是对活动预期结果的设想, 也是努力 的方向, 大学生为了实现创新创业梦而努力需要正能量和动力。聚合性。要聚合学校、企业、 教师、政府等各方面教学资源, 为创新创业课程目标的多样化服务, 才能够充分发挥各要素 的功能。反之, 如果课程目标模糊, 尽管相关有机体的各个要素都发挥出了自己最大的功能, 也难以达到提高大学生的全面素质, 促进大学生全面发展, 增加其能力, 为社会培养所需的 多样化人才的目标。多样性。“多样性” 是指课程目标实施结果的评价应该多样化。课程结 果的主要承载体是学生, 课程评价多样性工作的出发点和落脚点是学生的发展。课程评价多 样性包括了整个课程体系的所有的过程。通过课程评价多样性能够有效的对课程体系进行控 制, 从而起到激励导向和质量控制的作用。例如: 论文, 调查报告、计划书等等; 创造力的 考核可采用实践的方式、调研的方式等多种考核方式。评价教学效果时, 要考虑到各方面的 因素, 力图使考核变得更为客观、合理和科学公正。评价多样性可以增加学生的自信心, 看 到自己的进步, 看到自己的差距, 这都会对学习有促进作用。为了保证评价结果更加全面准 确, 在评价的过程中应该采用多样化的评价方法, 如个人与组织的评价、专家与社会的评价、 过程与结果的评价。操作性。创新创业课程的目标要很明确, 也要确保能够实现, 不能盲目 的立一个难以实现的目标, 必须要求操作性很强, 能够在学生努力下实现创新创业课程目标。 大跃进是人人都想实现的, 但却是一个空想的梦而已, 创新创业很艰辛, 目标的正确性, 可 操作性能够很大程度激励学生努力学习并实现创新创业梦想。交叉性。创新创业课程目标多 样化也体现了交叉性。现有的人才培养模式导致学生缺乏跨学科的知识, 知识基础薄弱、眼 光狭窄, 不会运用多学科的知识、方法发现问题和解决复杂问题, 创新创业能力弱、社会适 应能力差。学生毕业走向社会前, 如果不调整自己的知识结构、丰富自己的知识内容, 仅仅 依靠学校的知识, 是不能成为工作独挡一面并使事业持续发展的创新创业人才的。保障性。

“保障性” 是指要切实抓好创新创业教育工作, 提高创新创业人才培养水平, 必须要有一个 好的保障机制, 充分发挥组织、制度、师资力量和财力物力等方面的保障作用。系统性。“系 统性” 是指课程目标的系统性, 创新创业课程目标多样化是指高校应该努力构建多样化的创 新创业课程体系。综合性。“综合性” 是指在创新创业课程目标多样化改革中需要进行创新 创业教育综合改革。 


\section{3. 创新创业教学目标多样化的功能}

创新创业课程多样化的教学目标主要有以下功能：一、导学：确立创新创业教学目标。 第一, 以教材为基础, 确定教学内容。在确定课时教学目标前, 创新创业课程教师应当认真 研究教材, 了解每章节的目标设计与前后章节目标的关联性, 明确本章节教学目标到底在全 书中处于一个什么的地位与联系, 哪些知识内容应该为后面的学习做准备的, 这样我们才能 科学、合理地设定教学内容。第二, 以学情为基础设计目标。我们知道教学目标的完成者是 学生, 学生由于各自的知识结构、个性特点以及各自的学习需求的不同, 都影响教学目标的 实现。例如, 结合创新创业概述的创新创业管理的知识, 这些知识在课本当中都陆陆续续地 出现过, 学生也比较熟悉, 因此创新创业课程教师在新授前要激活学生已有知识, 把教学重 点引导在初创企业管理知识上去。针对知识的特点, 通过市场调研、走访企业等多种形式让 学生参与进来, 以帮助他们更好地掌握这些知识与技能。二、导教: 落实创新创业教学目标。 在这个过程中要注意提高大学生的运用知识的能力。创新创业课程教师在教学中不仅应当让 学生掌握每一章节的知识, 还应当根据每一章节知识和学生的实际水平拓展创新创业知识与 技能 ${ }^{[2]}$ 。三、导评：评价教学效果。教学目标怎么达到? 这必须通过课堂中的学生的表现才能 看出。创新创业课程的教师想知道学生是否已掌握本章本节知识点, 是否达成这章节教学目 标, 可以采用多种方式进行测评, 最常用的是课堂提问。在创新创业课程的巩固拓展环节可 以开展以下几种方式来实施评价: 方式一是案例分析法, 通过学生参与讨论以及在讨论中的表 现, 考查学生是否能准确使用。方式二是进行市场调研, 鼓励学生综合运用所学的知识编制 市场调查报告。方式三是利用软件进行模拟, 考查学生是否具有准确使用的技能。同时由于 学生间的差异是客观存在的, 针对不同学生的学习个性、心理、知识结构等特点, 灵活运用 多样化的分层题目检测学生对当堂知识的目标达成，对分层检测、分层作业的及时、恰当、 有针对性的教师评价。课程是围绕学习者而开展的, 主体是学生, 课程的基本职能是要促使 学生获得知识和技能, 并在此过程中使学生的身心得到发展。因此, 教育部门确定创新创业 课程目标时, 首先要掌握教育的时代背景、明确教育改革的发展走向、把握创新创业课程特 征、认真分析学生的实际状况, 制定符合现实要求的创新创业课程目标; 其次, 要处理好教 育与学校创新创业课程价值取向的关系, 不要混同, 否则, 容易发生混乱; 再次, 要避免政 绩化导向对创新创业课程目标的影响而偏离了创新创业课程应有的价值取向。只有这样, 制 定出来的创新创业课程目标才能被产业界、教育界的各位专家、学者和老师所认同和接受。

\section{4. 创新创业教学目标多样化的关注点}

确定不同阶段的阶段目标，总体目标和阶段性目标成为每所学校创新创业课程的设计、 实施和评价的重要依据, 但各校在实施过程中, 在目标的确定性和达成度方面存在较大的模 糊性和不确定性, 普遍感到心中无数, 难以把握。创新创业课程目标的实施过程的动态性和 不可预测性, 必然导致创新创业课程目标在实施过程中体现出多样化、多层面和生成性的特 点, 与学科教学目标的相对稳定、具体、可检测等相比, 操作难度较大, 成为实施创新创业 课程的一大困惑。依据创新创业课程的特性和实施中存在的困难, 在创新创业课程目标的确 定和把握方面应充分关注以下几点：一、目标的基础性和个性化。创新创业课程是满足每一 位大学生的个性需求, 面向全体大学生开设的必修课程, 每一位大学生都是课程的利益相关 者, 教师在指导大学生的过程中, 应善于观察和发现每一位大学生的个性特点和爱好, 结合 具体活动的特点, 帮助大学生建立合理的活动目标, 使目标既能体现对整体的关注, 又能顾 及每一位学生的基本利益。了解他们的综合素质和活动能力, 引导他们积极参与创新创业实 践活动, 使他们通过自己的努力达到一定目标, 从而不断唤醒他们内在的创新创业热情, 改 善他们在学校中的生活状态。二、目标的多样性和多向性。在知识与技能目标方面, 主要指 大学生通过参与各类活动获取对自然、社会和自我的整体认识, 进一步增强感性认识, 拓宽 知识面, 丰富自己的经验世界, 超越知识的系统性和学科界限的综合性。需要培养与他人的 
合作交流能力, 独立思考与探究能力, 动手操作能力, 组织与领导能力, 表达能力; 在情感 态度价值观目标方面, 主要指学生在创新创业实践过程中获取的内心体验和真实感受, 以及 形成的基本价值取向, 强调提升大学生的创新创业意识, 树立良好的学习态度、科学态度和 生活态度, 激发内在的求知欲, 增强责任感, 提高价值判断能力, 养成健全人格。三、目标 的开放性和生成性。以培养大学生择业意识、团队意识、竞争意识和增强社会责任感为目标 创新创业课程, 在把学生的学习生活、当今社会的变革、未来社会的发展趋势和个人的理想 紧密联系在一起, 打破学校教育长期自我封闭的局面, 使学生一下子站到了社会变革的最前 沿, 学生通过社会访谈、历史回顾、中外职业比较、社会问题剖析、择业与创新创业辩论等 主题活动了解社会, 关注自我, 增强责任, 课程目标也在课程的发展中不断调整, 动态生成。

正确建立并切实把握创新创业课程目标, 必须真正确立大学生在目标制定和目标达成过 程中的主体地位, 学生自己根据课程内容、学校总体要求和自身需求, 定下课程目标。教师 在大学生制定目标的过程中, 为大学生提供丰富的相关背景资料, 主动发现学生的兴趣和个 性特长, 主动与大学生联系和沟通, 为学生制定具有个性化的目标提出建议, 使课程目标具 有可操作性, 最后由师生共同确定课程目标。在实施中, 教师应认真记录并分析学生活动情 况，适时向学生反馈分析意见，并就下一段活动提出合理化建议。

\section{5. 创新创业教学多样化目标的确定步骤}

首先, 通读教材。首先是通读创新创业章节教学内容, 通过通读, 从整体上了解本书的 整体构建, 然后再去把握每一章节的内容, 理清章节与课程内容之间的关系。其次是精读每 章节的内容, 去把握每一章节的教学重点和难点。最后是熟读, 对要整体内容准确而又熟练 的把握。其次, 通读课标。了解课程标准这是确定多样化教学目标一个很重要的步骤, 因为 它规定了教学方向。再次, 分析学情。著名的教育专家于永正说： “因为我首先考虑的不是 学生将会怎样配合我教, 而是我的教如何去配合学生的学。因此, 创新创业教师制定教学目 标之前要了解学生的实际情况, 包括学生的知识结构、生活经历, 兴趣爱好、习惯方式等等。 怎样正确把握创新创业课程教学目标确定的依据, 是关系到整个创新创业课程进行能否正确 有效的关键。要通过和其他教师的共同合作甚至学校外的其他有关人员的合作来考虑确定教 学目标。要本着教学相长的原则, 与学生共同去学习、去实践, 通过实践活动和学生共同提 高。创新创业课程教学目标的确定的依据还有其他因素。在确定教学目标时这些主要因素综 合考虑才能正确地确定教学目标, 单独考虑某一个或几个都是不合适的。所以这就要求教师 在设定创新创业教学目标过程中可以尽量把内容具体细化。例如, 创新创业教材中每一章都 有教学要点, 它告诉学生和老师该单元的教学重点有哪些, 而这正是确定教学目标的另一个 依据。创新创业内容涉及的知识点很多, 哪些是教学重点, 哪些是在本课时中要解决的, 应 根据章节重点与老师上课的进度来定。

\section{References}

[1] Chen Yan, the construction of the differentiated instruction system of entrepreneurship education in Colleges , Journal of Jiamusi College of Education,2013(5):23-24.

[2] Lv Kaiyan, the strategy of Cultivating College Students' innovation and entrepreneurship ability, Liaoning economy,2014(6):50-51. 